\title{
Studies of modified carbon nanotubes by means of thermogravimetry Q-TG and sorptometry techniques
}

\author{
Piotr Staszczuk • Dagmara Zimmerman-Rysz
}

Received: 4 November 2013/Accepted: 22 September 2014/Published online: 16 October 2014

(c) The Author(s) 2014. This article is published with open access at Springerlink.com

\begin{abstract}
The paper presents the physicochemical (adsorption and porosity) properties of closed carbon nanotubes, opened through the action of an oxidizing acid and modified with metal ions of nickel, cobalt, and iron/ cobalt. The carbon nanotubes were prepared via the oxidation process by means of $65 \%$ nitric acid and/or nickel and cobalt nitrates dissolved with $65 \%$ nitric acid. Using special thermogravimetry Q-TG and sorptometry methods physicochemical properties of pure and modified nanotube surfaces were investigated. A numerical and analytical procedure for the evaluation of heterogeneous properties (adsorption capacity, statistical number of adsorbed liquid layers, desorption energy distribution functions) on the basis of liquid thermodesorption Q-TG from the sample surfaces under the quasi-equilibrium conditions are presented. The calculations of the specific surface areas, pore size and volume, and fractal dimensions of carbon nanotubes were made from sorptometry data.
\end{abstract}

Keywords Adsorption of metal ions - Total heterogeneity of carbon nanotubes . Thermogravimetry Q-TG .

Sorptometry

The present article is based on the lecture presented at CEEC-TAC conference in Vilnius, Lithuania 27-30 August, 2013.

P. Staszczuk $(\square)$

Department of Bionanomaterials, Faculty of Biotechnology and Science of Environmental, Institute of Biotechnology, The John Paul II Catholic University of Lublin, Konstantynów 1I Str, 20-708 Lublin, Poland

e-mail: pstaszczuk@kul.lublin.pl

D. Zimmerman-Rysz

Józef Piłsudski University of Physical Education in Warsaw, Marymoncka 34 Str, Warsaw, Poland

\section{Introduction}

Pure carbon nanotubes have extraordinary electrical, mechanical, physicochemical, and biological properties [1-7]. Mechanical, thermal, and physicochemical modifications applied to nanotubes reveal other equally surprising properties and widen prospects for different applications in the future [8]. The application of carbon nanotubes in bionanotechnology is promising owing to their many unique and favorable properties, from high tensile strength and high electrical conductivity to the ability to be wet by water [5,9]. There are many methods of obtaining these materials, but none leads to a homogenous product. Thin films of carbon nanotubes (CNTs) are fabricated from solution using a one-step directed assembly strategy [10]. Therefore, the nanotubes must be purified before the process of modification is applied. Products of synthesis contain various contaminants such as particles of the catalytic agent, small clasters of graphite, amorphous and turbostatic carbon, fullerenes, and carbon nanocapsules. The purification methods can be classified into two groups: destructive and non-destructive. The destructive method consists of a heat treatment over many hours in oxidizing substances, which not only causes an elimination of amorphous and turbostatic carbon but also the loss of mass of the sample and modification of the nanotubes through the opening of their ends. Acid purification method of single-walled carbon nanotubes (SWCN) proved to be effective, resulting in a threefold increase in the percentage of SWNTs present in the purified product as determined by thermogravimetric analysis [11]. The opening of nanotubes changes a whole range of properties, mainly the effective surface area. The action of the oxidizing agents also causes the appearance at the 
nanotube ends of various functional groups. The remains of the catalytic agent are often removed through the action of concentrated acids. Non-destrictive methods clean carbon nanostructures without causing damage to their morphology. This is especially important from the point of view of electronics which is one of the key areas in which carbon nanotubes are predicted to play an important role. Multi-walled carbon nanotubes are utilized in a number of sectors as a result of their favorable electronic properties. Engineered nanomaterials are finding application in a wide range of consumer electronics [12, 13].

Most multi-walled nanotubes are closed at both ends with multi-walled or spherical cupolas [14]. This presents adsorption and inhibits the capillary process in the pores of the internal walls of the graphene layers and in the cane itself. Because of this, various techniques for opening the nanotubes are used $[15,16]$. These include ultrasonic bathing, shaking in a ball mill, and heat treatment in oxidizing agents. The mechanism of opening is associated with the presence of chemical defects in the nanotubes (heteroatoms in the nanotube structure) and structural features (existence of pentagons and heptagons in the hexagonal layers). At the ends of the nanotubes, surfaces with reactive bonds are created. The carbon-carbon bonds in such areas undergo significant stresses. This is the reason why they enter easier into chemical reactions, and nitric acid attacking them causes detachment of cupolas and the opening of the nanotubes. The next phase of modification of the nanotubes was the filling of their cores with cations of metals, such as iron, nickel, and cobalt [17]. Using special thermogravimetry (Q-TG), sorptometry, and AFM methods physicochemical properties of pure and modified by nitric acid and/or ferric nitrate nanotube surface were investigated [18].

The focus of this work was an evaluation of the adsorptive features and the roughness of clean and modified surfaces of carbon nanotubes. Nanotubes ends were spend by boiling in concentrates aqueous nitric acid following by mechanical degradation (grinding in a mortar). The next phase of modification of the nanotubes was the filling of their cores with ions of metals using nickel, cobalt, and $\mathrm{Fe} / \mathrm{Co}$ nitrates.

\section{Experimental}

\section{Materials}

The carbon nanomaterial samples obtained from SigmaAldrich were experimentally tested:
- $\mathrm{C} 0$ - pure multi-wallet carbon nanotubes; $\mathrm{OD}=60-100 \mathrm{~nm}, \mathrm{ID}=50-10 \mathrm{~nm}, l=0,5-500 \mu \mathrm{m}$.

- C1-sample C0 modified by treatment with concentrated aqueous nitric acid.

- $\mathrm{C}-\mathrm{Ni}$-sample $\mathrm{C} 0$ modified by treatment with concentrated aqueous nitric acid and impregnated in nickel nitrate in amount $0,4 \mathrm{mmol} \mathrm{g}^{-1}$ nanomaterial.

- $\mathrm{C}-\mathrm{Co}-$ sample $\mathrm{C} 0$ modified by treatment with concentrated aqueous nitric acid and impregnated in cobalt nitrate in amount $0,4 \mathrm{mmol} \mathrm{g}^{-1}$ nanomaterial.

- $\mathrm{C}-\mathrm{Fe} / \mathrm{Co}$ - sample $\mathrm{C} 0$ modified by treatment with concentrated aqueous nitric acid and impregnated in iron nitrate in amount $0,4 \mathrm{mmol} \mathrm{g}^{-1}$ nanomaterial and cobalt nitrate in amount $0,2 \mathrm{mmol} \mathrm{g}^{-1}$ nanomaterial.

\section{Modification}

The first stage of modification of samples of multi-walled carbon nanotubes was the removal of the cupolas, the tips of the nanotubes, through the action of nitric acid.

The modification was conducted in a round-bottomed flask, containing $8 \mathrm{~g}$ of nanotubes and $1,200 \mathrm{~mL}$ of $65 \%$ aqueous nitric acid solution. The process of heating at temperature of $120^{\circ} \mathrm{C}$ under a reflux condenser lasted for $24 \mathrm{~h}$. Next the acid was drained from above the sediment and the mixture with filtered using a filter of Whatman glass microfibers, class $\mathrm{GF} / \mathrm{F}$, with pore size of $0.7 \mu \mathrm{m}$ and a water pump. The nanotube sediment obtained was washed several times with distilled water and then dried at room temperature for $12 \mathrm{~h}$. The next stage consisted in filling the cores of the open nanotubes with metal ions. For that purpose, weighed portions of $0.8 \mathrm{~g}$ were prepared, to which suitable amounts of nickel nitrate(II), cobalt nitrate(II), and Fe/Co nitrates were added. Samples prepared in this manner were shaken in test tubes for $24 \mathrm{~h}$ at room temperature. Then, all samples were filtered using a filter of Whatman glass microfibers, without washing the sediment remaining on the filter. The next stage was the drying of the sample at temperature of $100{ }^{\circ} \mathrm{C}$ for $12 \mathrm{~h}$, and subjecting them to calcination at $450{ }^{\circ} \mathrm{C}$, in an argon atmosphere, with increase in temperature gradient of not more than $5{ }^{\circ} \mathrm{C} \min ^{-1}$, over a period of $5 \mathrm{~h}$.

\section{Methods}

The thermodesorption process of a non-polar and polar ( $n$ octane, toluene, water) liquids from the surface of the synthesized material was studied [19] using a Derivatograph of Q-1500D type (MOM, Hungary) [20]. The samples were saturated with liquid vapors in a vacuum desiccator where $p / p_{\mathrm{o}}=1$ for $24 \mathrm{~h}$, to establish the state of 
liquid adsorption equilibrium. The gel samples were removed to the measuring crucible placed in the furnace of the Derivatograph and 3 measurements were made in the temperature range of $20-250{ }^{\circ} \mathrm{C}$ with a heating rate of $6{ }^{\circ} \mathrm{C} \min ^{-1}$; measurements close to the average value were taken for the calculations. Additionally, porosity properties, e.g., specific surface areas, pore size distribution, and pore size and volume were calculated from low temperature nitrogen adsorption-desorption isotherms measured by means of the Sorptomat ASAP 2405 V1.01 with special program for preparation of the isotherms (Micrometrics Co., USA). Based on the above experimental data, adsorption capabilities as well as total (geometrical and energetic) surface heterogeneity of the studied samples were determined [21].

\section{Calculations}

Determination of geometrical heterogeneity and adsorption capacity of the surface carbon nanotubes from Q-TG and sorptometry data

Analysis of Q-TG curves from the process of thermodesorption of $n$ octane, toluene, and water, as well as data of specific surface areas from the sorptometry technique, permits the calculation of the total adsorption capacity of the samples and number of monolayers of those liquids that were present on the surface of carbon nanotubes. The parameters calculated depend significantly on the method of modification of the samples.

Estimation of the energetic heterogeneity from Q-TG data

The method of programed liquid thermodesorption from the surface of studied solids can be used for calculation of desorption energy and presentation of the desorption energy distribution function in a graphical form. Monomolecular desorption kinetics in the case of unassociated one-component layers is described by the equation [18]:

$-\frac{\mathrm{d} \theta}{\mathrm{d} t}=v(1-\theta) \exp \left(-\frac{E_{\mathrm{d}}}{R T}\right)$,

where

$T=T_{0}+\beta t$

$R$ is the universal gas constant, $\theta$ is the degree of surface coverage, $v$ is the entropy factor, $E_{\mathrm{d}}$ is the desorption energy calculated for each temperature, $T_{0}$ and $T$ are the initial and given temperatures of desorption, respectively, $\beta$ is the heating rate of the sample, and $t$ is the time.
Equation (3) holds for the case when the amount of desorbed substance does not fill the whole surface uniformly; however, desorption takes place in the range of capillary condensation. The above equation can also be used for the analysis of desorption from the multilayer filled energetically heterogeneous surface of the studied material. Then the desorption rate is described by the integral equation:

$-\frac{\mathrm{d} \theta}{\mathrm{d} T}=\int_{E_{d}} \phi\left(E_{\mathrm{d}}\right)(1-\theta) \frac{v}{\beta} \exp \left(-\frac{E_{\mathrm{d}}}{R T}\right) \mathrm{d} E_{\mathrm{d}}$.

Energetic heterogeneity of the solid surface is described by the energy distribution function $\varphi\left(E_{\mathrm{d}}\right)=\mathrm{f}\left(E_{\mathrm{d}}\right)$. In other words, this is the density of adsorption center distribution probability on the surface of the studied sample in relation to the quantity of desorption energy.

The logarithmic form of the initial equation is expressed by the following formula:

$\ln \left[-\frac{1}{(1-\theta)} \cdot \frac{\mathrm{d} \theta}{\mathrm{d} T}\right]=\mathrm{f}\left(\frac{1}{T}\right)$.

The final expression to determine the density function $\varphi\left(E_{\mathrm{d}}\right)$ can be presented as

$\phi\left(E_{d}\right)=\frac{\mathrm{d} \theta}{\mathrm{d} T} \cdot \frac{1}{T}$.

Estimation of fractal coefficients of surface of carbon nanotubes from sorptometry data

The geometry heterogeneity was studied on the basis of calculation of volumetric fractal coefficients [17, 22]. Their determination is important for the processes of diffusion and adsorption, as well as for chemical reactions and catalysis [18, 23]. They are determined from data of sorptomatic analysis [24]. The volumetric fractal coefficients were calculated with the method of Frenkel, Helsay, Hill, and Kisielev, from the following equations [18, 25]:

$D_{\mathrm{f}}=2+n_{\mathrm{f}}$

$D_{\mathrm{f}}=3-\frac{\mathrm{d}[\ln (a(x))]}{\mathrm{d}[\ln (-\ln (x))]}$,

where $n_{\mathrm{f}}$ is the part of fractal dimension, $a$ is the value of adsorption, and $x$ is the section of experimental isotherm.

\section{Results and discussion}

The surface parameters of the initial sample of multiwalled carbon nanotubes ( $\mathrm{C} 0$ ) and of the samples after modification with oxidizing acid and with the nitrates of metals $(\mathrm{C} 1, \mathrm{C}-\mathrm{Ni}, \mathrm{C}-\mathrm{Co}, \mathrm{C}-\mathrm{Fe} / \mathrm{Co})$ were determined on the basis of nitrogen adsorption isotherms (Fig. 1). The 


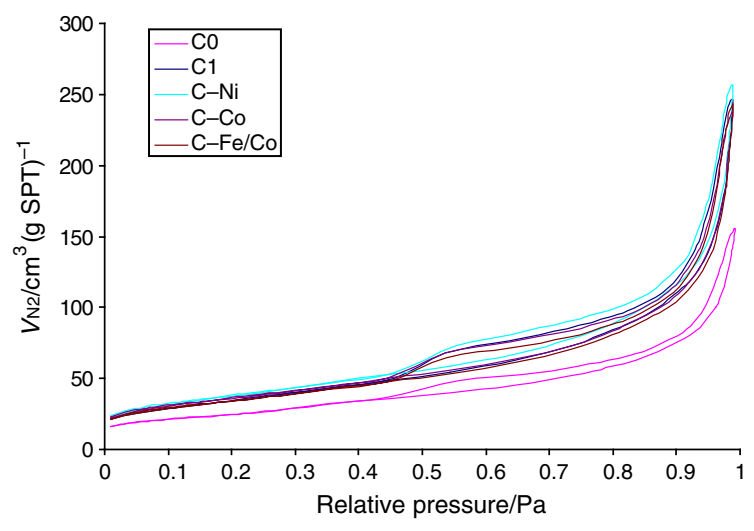

Fig. 1 Nitrogen adsorption/desorption isotherm for all samples

isotherms obtained are classified as type II according to the BET classification [26, 27]. The increase in the concentration of the adsorbate in the gas phase caused gradual filling of pores with larger and larger diameters, and the formation of a multi-molecular adsorption layer. The existence of the hysteresis loop indicates the presence of open pores in the structure of the material. The number of pores available in the material modified with nitric acid was higher than that in the samples that were not subjected to the effect of the oxidizing factor. The expansion of the hysteresis loop in the case of samples $\mathrm{C} 1, \mathrm{C}-\mathrm{Ni}, \mathrm{C}-\mathrm{Co}$, and $\mathrm{C}-\mathrm{Fe} / \mathrm{Co}$ confirms the phenomenon of opening of nanotubes. The amount of vapors adsorbed on the initial material (C0) was the smallest, at $155 \mathrm{~cm}^{3} \mathrm{~g}^{-1}$, while for the sample heated in nitric acid (C1), the corresponding value was $247 \mathrm{~cm}^{3} \mathrm{~g}^{-1}$. For the remaining samples subjected to modification with nitric acid and with the metal nitrates $(\mathrm{C} 1, \mathrm{C}-\mathrm{Ni}, \mathrm{C}-\mathrm{Co}, \mathrm{C}-\mathrm{Fe} / \mathrm{Co})$, the values of adsorption varied within the range of $241-268 \mathrm{~cm}^{3} \mathrm{~g}^{-1}$.

Based on the nitrogen adsorption-desorption isotherms, determination was made of the parameters describing the structure of the nanomaterials, i.e., specific surface area $(S)$, total pore volume $(V)$, mean pore diameter $(D)$, and the pore volume distribution functions $\mathrm{d} V / \mathrm{d} R=f(R)$. The mean pore radius and the pore volume of samples were calculated from the desorption isotherms using the Barrett-Joyner-Holend (BHJ) method, and the specific surface areas from the Brunauer-Emmett-Teller (BET), Langmuir and BJH theories and methods [26, 27].

The study showed a significant effect of the modification on the structural parameters of the nanomaterials (Table 1). The process of annealing in nitric acid caused an increase in the specific surface area of the studied material 1.5 -fold, from 88 to $122 \mathrm{~m}^{2} \mathrm{~g}^{-1}$ per sample, i.e., $150 \%$. This results from an increase in the nanotube inner surface area accessible to the adsorbate, thanks to the newly opened tips, and to changes in the aggregate structure due to the shortening of nanotubes at inflection points. In the case of samples C$\mathrm{Co}$ and $\mathrm{C}-\mathrm{Fe} / \mathrm{Co}$, the increase in specific surface area is $3-5 \mathrm{~m}^{2} \mathrm{~g}^{-1}$, and in the case of sample $\mathrm{C}-\mathrm{Ni}$ is $13 \mathrm{~m}^{2} \mathrm{~g}^{-1}$ in relation to sample $\mathrm{C} 1$. We suppose that the greater increase in specific surface area in the case of the sample modified with nickel ions is related to the formation of crystals of the metal on the nanotube surfaces. As a result of metal deposition on the surface of the initial material, a decrease in pore diameters was observed, and an increase in the volume of micropores in all the cases (Table 1).

The increase in the size of the specific surface area of $\mathrm{C}-$ $\mathrm{Ni}, \mathrm{C}-\mathrm{Co}$, and $\mathrm{C}-\mathrm{Fe} / \mathrm{Co}$ samples in relation to $\mathrm{C} 1$ sample resulted in the reduction of pore diameter from $104 \AA$ to $94 \AA$ due to closer packing of the aggregate structure in the process of calcinations and because of the growth in the content of metal. The size of the surface of micropores ( $\left.S_{\text {MICRO }}\right)$ of the baseline sample and the sample modified with nitric acid have not changed significantly. The drawn diagrams of the pore size distribution function (Fig. 2) show that the tested materials belong to mesoporous adsorbents $(D=2-50 \mathrm{~nm})$. The obtained curves are bimodal curves of the Gaussian type.

After the process of the modification of baseline sample with nitric acid, changes in the height of peaks are observed. The main peak with its maximum of $2.1 \mathrm{~nm}$ is

Table 1 Changes in the porosity parameters from the nitrogen adsorption-desorption isotherms describing the structure of the surface of the nanomaterials studied

\begin{tabular}{|c|c|c|c|c|c|c|c|c|c|}
\hline Samples & $\begin{array}{l}\text { Contents of } \\
\text { metal/\% }\end{array}$ & $\begin{array}{l}\text { Nitrogen/ } \\
\mathrm{cm}^{3} \mathrm{~g}^{-1}\end{array}$ & $\begin{array}{l}S_{\mathrm{BET}} / \\
\mathrm{m}^{2} \mathrm{~g}^{-1}\end{array}$ & $\begin{array}{l}S_{\text {MICRO }} \\
\mathrm{m}^{2} \mathrm{~g}^{-1}\end{array}$ & $\begin{array}{l}V_{(\mathrm{ads}) \mathrm{BJH}} / \\
\mathrm{cm}^{3} \mathrm{~g}^{-1}\end{array}$ & $\begin{array}{l}V_{(\mathrm{des}) \mathrm{BJH}} / \\
\mathrm{cm}^{3} \mathrm{~g}^{-1}\end{array}$ & $\begin{array}{l}V_{\mathrm{MICRO} /} / \\
\mathrm{cm}^{3} \mathrm{~g}^{-1}\end{array}$ & $\begin{array}{l}D_{\mathrm{Av}} / \\
\AA\end{array}$ & $\stackrel{\circ}{\mathrm{BJH}}^{D /}$ \\
\hline $\mathrm{C} 0$ & - & 155.2 & 88 & 4 & 0.24 & 0.24 & 0.002 & 91 & 98 \\
\hline $\mathrm{C} 1$ & - & 246.7 & 122 & 5 & 0.39 & 0.38 & 0.001 & 104 & 113 \\
\hline $\mathrm{C}-\mathrm{Ni}$ & 9.47 & 255.7 & 135 & 9 & 0.40 & 0.39 & 0.004 & 94 & 111 \\
\hline $\mathrm{C}-\mathrm{Co}$ & 9.15 & 237.7 & 128 & 10 & 0.37 & 0.36 & 0.004 & 94 & 109 \\
\hline $\mathrm{C}-\mathrm{Fe} / \mathrm{Co}$ & $8.14 / 3.91$ & 241.9 & 125 & 9 & 0.38 & 0.37 & 0.004 & 96 & 116 \\
\hline
\end{tabular}




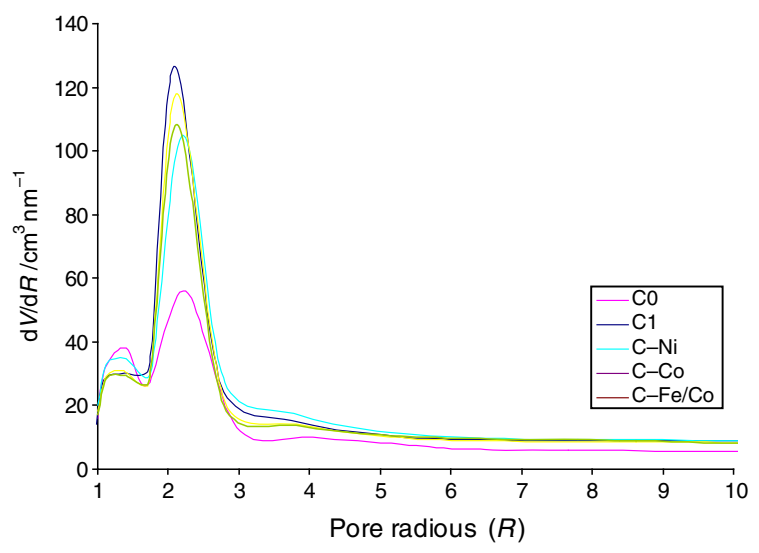

Fig. 2 Curves of the pore size distribution functions $(\mathrm{d} V / \mathrm{d} R$ in relation to their radius $R$ in $\mathrm{nm}$ ) for all modified samples

extended due to the increase in the number of pores with their diameters of a given size. These pores have the biggest contribution to the porosity of a given material. In the case of a side peak, a slight decrease in its height is observed. When comparing the function curves of the distribution of pores modified with acid and meal ions $(\mathrm{C}-$ $\mathrm{Ni}, \mathrm{C}-\mathrm{Co}, \mathrm{C}-\mathrm{Fe} / \mathrm{Co}$ ) to $\mathrm{C} 1$ sample, a relationship opposite to the one described above is noticeable: the height of a main peak decreases, while the height of a side peak increases.

Due to the complexity of the tested systems, in order to assess the adsorptive properties, the thermal desorption of polar (water) and non-polar liquids ( $n$ octane, toluene) were used [28]. The penetration of liquid vapor molecules into nanotubes occurs through their pentagonal ends or through their surface defects in the form of the coupled pairs of "pentagonal/heptagonal ring". Curves of mass loss (Q-TG) and differential curves (Q-DTG) of the thermal desorption of liquids from the tested of chosen surfaces are shown in the Figs. 3-5. The Q-DTG curves obtained during the studies of the thermal desorption of the above-mentioned liquids describe the energy levels of the molecules of these liquids located in intra- and intercrystallite pores of the coal material structure and in the inner pores of the nanotubes themselves. The energy of the interaction between adsorbate and adsorbent molecules depends on the type of the adsorbate, the surface properties of the adsorbent, and the porosity of the sample. The bigger the bandwidth of the Q-DTG is, the bigger the energetic differentiation of the "adsorbent/ adsorbate" system is. It can be observed in the charts of the thermal desorption of $n$ octane from the surface of the tested samples.

The existence of low temperature inflection in Fig. 3 at $140{ }^{\circ} \mathrm{C}$, second peak in Fig. 4 at $132{ }^{\circ} \mathrm{C}$, and inflection in Fig. 5 at $135^{\circ} \mathrm{C}$ on Q-DTG curves may be ascribed to the differences in bonding energy of liquids in adsorbed films on the carbon nanotube surfaces. The liquids desorbed in these regions have modified the properties due to strong interactions to the metal ions. The experimental results presented in Figs. 3, 4, and 5 suggest that desorption of liquids from the studied surfaces occurs in few steps.

On the basis of Q-TG curves, the adsorption capacity and the statistical number of monolayers are determined and presented in Table 2. During the first stage of modification using nitric acid, the increase of the adsorption capacity and the statistical number of monolayers were observed for all liquids. On one hand, it results from the increase of the specific surface area as a result of opening of the ends of closed nanotubes, while on the other-from the change in the nature of the surface, connected with the
Fig. 3 Thermal desorption of water from the surface of $\mathrm{C}-\mathrm{Ni}$ sample in quasi-static conditions

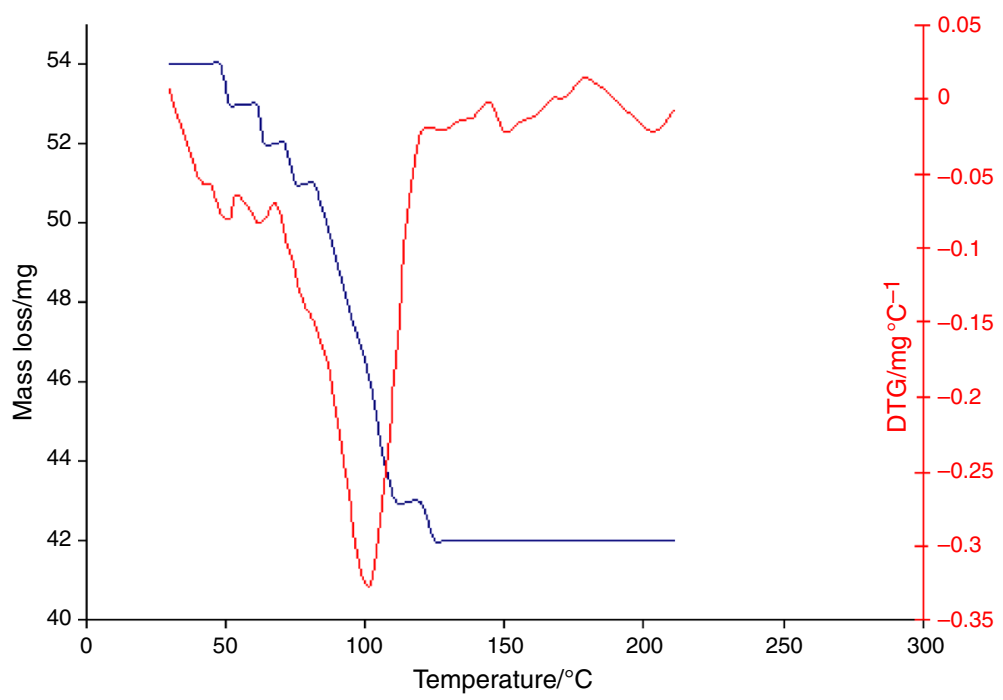


Fig. 4 Thermal desorption of toluene from the surface of $\mathrm{C}-$ Co sample in quasi-static conditions

Fig. 5 Thermal desorption of $n$ octane from the surface of $\mathrm{C}-$ $\mathrm{Fe} / \mathrm{Co}$ sample in quasi-static conditions
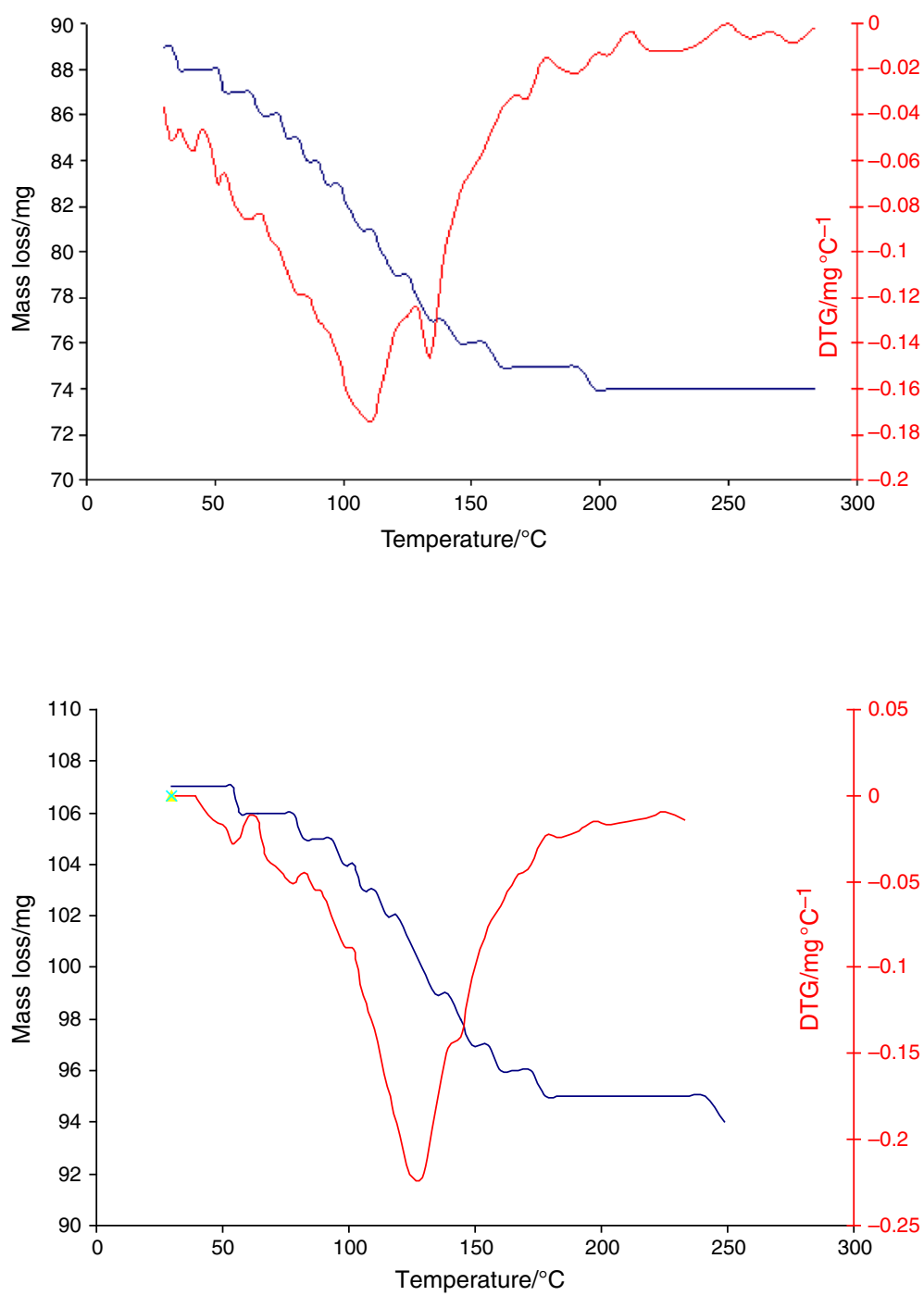

Table 2 Adsorption capacity of the samples $\left(a_{\max }\right.$ in $\mathrm{mg} \mathrm{mg}^{-1}$ and in $\left.\mathrm{mmol} \mathrm{g}^{-1}\right)$ and statistical liquid monolayers on sample surfaces

\begin{tabular}{|c|c|c|c|c|c|c|c|c|c|}
\hline \multirow[t]{2}{*}{ Samples } & \multicolumn{3}{|l|}{$n$ octane } & \multicolumn{3}{|l|}{ Toluene } & \multicolumn{3}{|l|}{ Water } \\
\hline & $a_{\max } / \mathrm{mg} \mathrm{mg}^{-1}$ & $a_{\max } / \mathrm{mmol} \mathrm{g}^{-1}$ & $n$ & $a_{\max } / \mathrm{mg} \mathrm{mg}^{-1}$ & $a_{\max } / \mathrm{mmol} \mathrm{g}^{-1}$ & $n$ & $a_{\max } / \mathrm{mg} \mathrm{mg}^{-1}$ & $a_{\max } / \mathrm{mmol} \mathrm{g}^{-1}$ & $n$ \\
\hline $\mathrm{CO}$ & 0.27 & 2.38 & 6.9 & 0.56 & 6.09 & 19 & 0.36 & 20.11 & 17.3 \\
\hline $\mathrm{C} 1$ & 0.30 & 2.67 & 5.6 & 0.79 & 8.46 & 15 & 0.28 & 15.69 & 9.7 \\
\hline $\mathrm{C}-\mathrm{Ni}$ & 0.45 & 39.59 & 7.5 & 0.16 & 17.23 & 3.5 & 0.23 & 12.63 & 7.1 \\
\hline $\mathrm{C}-\mathrm{Co}$ & 0.17 & 13.3 & 3.0 & 0.17 & 18.01 & 3.9 & 0.16 & 9.14 & 5.3 \\
\hline $\mathrm{C}-\mathrm{Fe} / \mathrm{Co}$ & 0.19 & 16.97 & 3.6 & 0.24 & 26.05 & 5.9 & 0.19 & 10.5 & 6.5 \\
\hline
\end{tabular}

emergence of functional groups, including carboxyl and hydroxyl group. A further modification with metal ions resulted in a significant decrease of the adsorptive capacity and the statistic number of monolayers, especially for the adsorption of toluene and water. The rapid decrease in the amount of the adsorbed toluene and water on the samples modified with metals indicates a change in the nature of active sites on the centers. The calculated adsorption capacity decreases because of the decrease in specific surface areas as follows (in $\mathrm{mg} \mathrm{mg}^{-1}$ ): 
$n$ octane: $\mathrm{C}-\mathrm{Ni}>\mathrm{C} 1>\mathrm{C} 0>\mathrm{C}-\mathrm{Fe} / \mathrm{Co}>\mathrm{C}-\mathrm{Co}$, toluene: $\mathrm{C} 1>\mathrm{C} 0>\mathrm{C}-\mathrm{Fe} / \mathrm{Co}>\mathrm{C}-\mathrm{Co}>\mathrm{C}-\mathrm{Ni}$, water: $\mathrm{C} 0>\mathrm{C} 1>\mathrm{C}-\mathrm{Ni}>\mathrm{C}-\mathrm{Fe} / \mathrm{Co}>\mathrm{C}-\mathrm{Co}$.

Using Q-TG curves of mass loss and their differential Q-DTG curves, the desorption energy distribution function was calculated using method described in the work [29] from Eqs. 1-5. The calculated data are presented in the Figs. 6 and 7. These results are presented in the shape of a Gaussian curve with one clear peak, which indicates the existence of one main active site on the surface of the adsorbent. Broadening of bands on the desorption energy distribution curves indicates the increase of energetic heterogeneity of the studied materials after nitric acid modification. The higher values the function of the distribution takes, the more active sites of a given energy are there on the surface of a solid. A high degree of non-linearity of the distribution function results from a high heterogeneity of energy of a studied material.
In Table 3, values describing the energetic heterogeneity parameters of the samples are compared, as well as the value of the desorption energy at its peak maximum $\left(\Delta E_{\mathrm{dmax}}\right)$, the value of a derivative in its maximum $\left\{\varphi\left(E_{\mathrm{d}}\right)_{\max }\right\}$, and the ranges at the peak maximum $\left(\Delta E_{\mathrm{d}}\right)$. The desorption energy distribution functions of samples modified with ions are different in the shape of the curves and the values of the desorption energy. They describe the probability density of the distribution of active sites on the surface in relation to the volume of the desorption energy. The presented distribution functions indicate a complex mechanism of the desorption process and the influence of the modification method, as well as metal ions on the surface properties of a nanomaterial. For particular liquids, the strength of the interaction with the surface changes $\left(\varphi\left(E_{\mathrm{d}}\right)_{\max }\right.$, in mmol $\mathrm{kJ}^{-1}$ ) in the series:

-/for $n$ octane: $\mathrm{C} 0>\mathrm{C} 1>\mathrm{C}-\mathrm{Fe} / \mathrm{Co}>\mathrm{C}-\mathrm{Ni}>\mathrm{C}-\mathrm{Co}$, -/for toluene: $\mathrm{C} 0>\mathrm{C}-\mathrm{Fe} / \mathrm{Co}>\mathrm{C}-\mathrm{Ni}>\mathrm{C}-\mathrm{Co}>\mathrm{C} 1$,
Fig. 6 Desorption energy distribution function on the $\mathrm{C} 0$ surface of samples for $n$ octane
Fig. 7 Desorption energy distribution function on the $\mathrm{CO}$ surface of samples for water
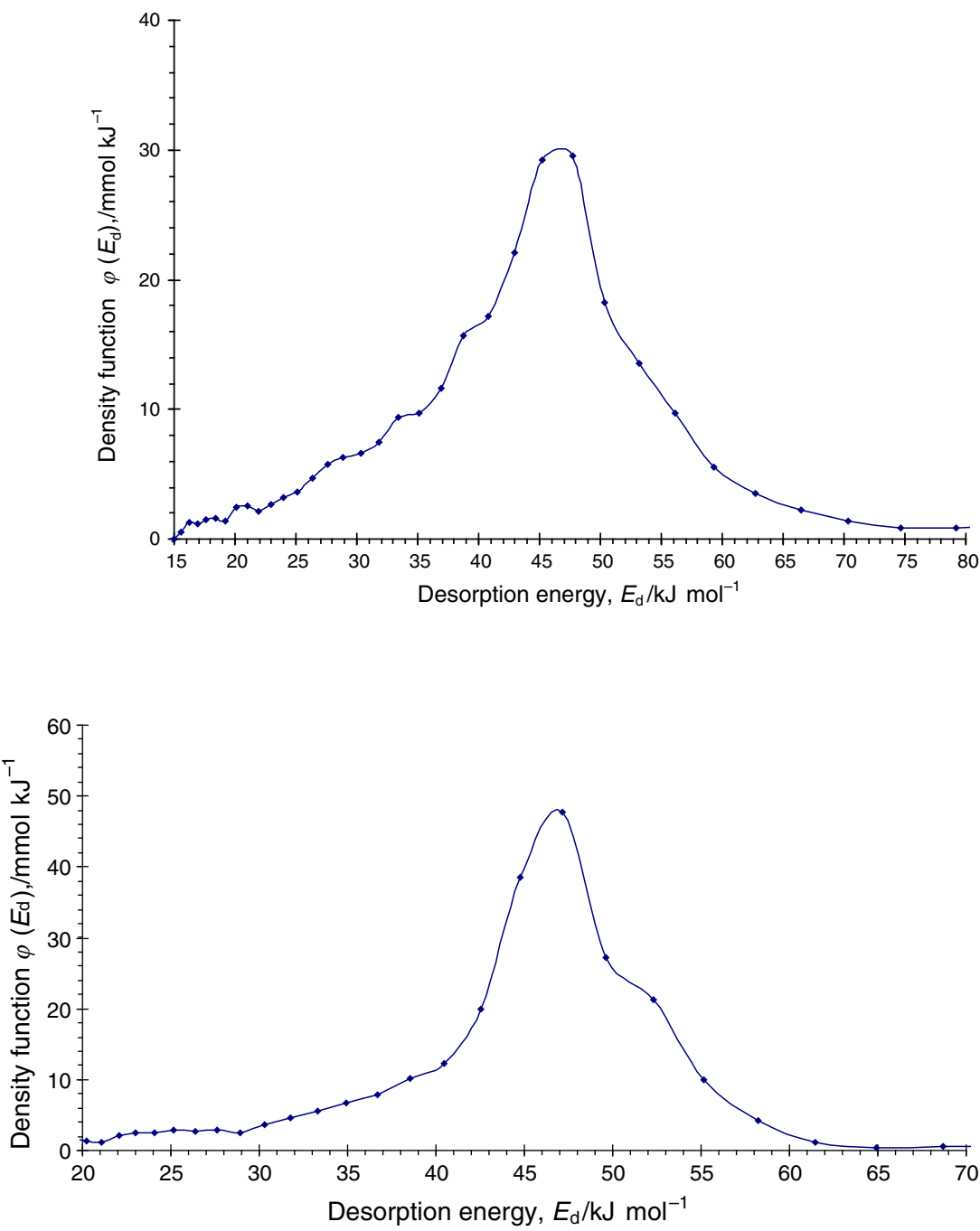
Table 3 The comparison of the properties of desorption energy changes of $E_{\mathrm{dmax}}, \Delta E_{\mathrm{d}}\left(\mathrm{kJ} \mathrm{mol}^{-1}\right)$, and $\varphi\left(E_{\mathrm{d}}\right)_{\max }\left(\mathrm{mmol} \mathrm{kJ}{ }^{-1}\right)$ for particular samples

\begin{tabular}{|c|c|c|c|c|c|c|c|c|c|}
\hline \multirow[t]{2}{*}{ Samples } & \multicolumn{3}{|l|}{$n$ octane } & \multicolumn{3}{|l|}{ Toluene } & \multicolumn{3}{|l|}{ Water } \\
\hline & $\begin{array}{l}E_{\mathrm{dmax}} / \\
\mathrm{kJ} \mathrm{mol}^{-1}\end{array}$ & $\begin{array}{l}\varphi\left(E_{\mathrm{d}}\right)_{\max } / \\
\mathrm{mmol} \mathrm{kJ}^{-1}\end{array}$ & $\begin{array}{l}\Delta E_{\mathrm{d}} / \\
\mathrm{kJ} \mathrm{mol}^{-1}\end{array}$ & $\begin{array}{l}E_{\mathrm{dmax}} / \\
\mathrm{kJ} \mathrm{mol}^{-1}\end{array}$ & $\begin{array}{l}\varphi\left(E_{\mathrm{d}}\right) \text { max } / \\
\mathrm{mmol} \mathrm{kJ}^{-1}\end{array}$ & $\begin{array}{l}\Delta E_{\mathrm{d}} / \\
\mathrm{kJ} \mathrm{mol}^{-1}\end{array}$ & $\begin{array}{l}E_{\mathrm{dmax}} / \\
\mathrm{kJ} \mathrm{mol}^{-1}\end{array}$ & $\begin{array}{l}\varphi\left(E_{\mathrm{d}}\right)_{\max } / \\
\mathrm{mmol} \mathrm{kJ}^{-1}\end{array}$ & $\begin{array}{l}\Delta E_{\mathrm{d}} / \\
\mathrm{kJ} \mathrm{mol}^{-1}\end{array}$ \\
\hline $\mathrm{C} 0$ & 47.2 & 30.1 & 22.1 & 35.8 & 32.5 & 36.6 & 46.9 & 48.3 & 45.6 \\
\hline $\mathrm{C} 1$ & 47.7 & 29.6 & 20.2 & 45.6 & 19.1 & 19.4 & 47.1 & 47.7 & 29.3 \\
\hline $\mathrm{C}-\mathrm{Ni}$ & 30.1 & 12.3 & 23.8 & 29.3 & 22.3 & 24.5 & 37.6 & 19.8 & 43.7 \\
\hline $\mathrm{C}-\mathrm{Co}$ & 28.5 & 6.4 & 28.3 & 28.1 & 21.1 & 25.5 & 37.7 & 19.4 & 30.7 \\
\hline $\mathrm{C}-\mathrm{Fe} / \mathrm{Co}$ & 33.9 & 8.9 & 32.4 & 37.3 & 31.1 & 26.6 & 44.3 & 33.6 & 34.9 \\
\hline
\end{tabular}

Table 4 Values of fractal coefficients calculated on the basis of Eqs. (1) and (2) and the nitrogen adsorption-desorption isotherms

\begin{tabular}{llll}
\hline Samples & \multicolumn{4}{l}{ Sorptometry method } \\
\cline { 2 - 4 } & Eq. (1) & Eq. (2) & Average \\
\hline $\mathrm{C} 0$ & 2.52 & 2.45 & 2.48 \\
$\mathrm{C} 1$ & 2.64 & 2.56 & 2.60 \\
$\mathrm{C}-\mathrm{Ni}$ & 2.65 & 2.55 & 2.60 \\
$\mathrm{C}-\mathrm{Co}$ & 2.64 & 2.57 & 2.61 \\
$\mathrm{C}-\mathrm{Fe} / \mathrm{Co}$ & 2.64 & 2.56 & 2.60 \\
\hline
\end{tabular}

-/for water: $\mathrm{C} 0>\mathrm{C} 1>\mathrm{C}-\mathrm{Fe} / \mathrm{Co}>\mathrm{C}-\mathrm{Ni}>\mathrm{C}-\mathrm{Co}$.

The high value of the desorption energy of liquids from C0 sample indicates great influence of the surface on the adsorbed molecules. It depends on radius and charge of adsorbed metal ions and its physical properties. The increase of desorption energy, $\varphi\left(E_{\mathrm{d}}\right)_{\max }$, for toluene and water (Table 3 ) in relation to $n$ octane is evidence of an increase of the adsorbent-adsorbate interaction of forces. The high values of desorption energy of $\mathrm{C} 0, \mathrm{C} 1$, and $\mathrm{C}-\mathrm{Fe} /$ Co samples indicate great influence of surface active carbon centers on the adsorbed liquid molecules. The thermodesorption processes of above liquids show that the investigated materials after $\mathrm{Ni}, \mathrm{Co}$, and $\mathrm{Fe} / \mathrm{Co}$ ions modification have less energetic surface heterogeneity properties than $\mathrm{Co}$ and $\mathrm{C} 1$ samples. The above treatment resulted in creation of low-energy adsorption sites for the adsorbed molecules. For aromatic hydrocarbon molecules (toluene), a considerable increase of the value of the energy of desorption occurred in creation high-energy adsorption sites for liquid molecules. However, the changes in the desorption energy and desorption energy distribution functions that occur as a result of chemical treatment appear somewhat complicated and require future studies.

One of the parameters describing geometry heterogeneity is fractal coefficients. They are calculated on the basis of the nitrogen adsorption isotherms, using Eqs. (6) and (7) and presented in Table 4.
The average value of calculated volume fractal coefficients for an unmodified sample was 2.48 . Further modification, the opening of nanotubes and the modification of metal ions, resulted in the increase of this value to 2.55-2.65. From the data presented in Table 4, it appears that bigger fractal coefficients have been obtained for bigger surface areas of surface studied. Differences in the values of fractal coefficients for the modified samples indicate an important influence of metal ions on the porosity of the surface, especially specific surface areas and pore radius and volumes. It is connected with size and charge of the attached metals. On the other hand, fractal dimension is not sensitive parameter for study of the porosity of surface nanomaterials.

\section{Conclusions}

The study of effect of modification of carbon nanotube surfaces by nitric acid and $\mathrm{Ni}, \mathrm{Co}$, and $\mathrm{Fe} / \mathrm{Co}$ ions with respect of $n$ octane, toluene and water wettability, and formation of adsorbed liquid films are presented. The special Q-TG thermal analysis and low temperature nitrogen adsorption-desorption sorptometry techniques for studying total (geometrical and energetical) surface heterogeneity were used. It follows that chemical modification of samples causes not only changes in porosity (adsorption capacity, pore radius and volume, and specific surface areas) but also in significant properties in respect to the desorption energy and desorption energy distribution functions of non-polar and polar liquids. The change in number of active sites on modified surfaces may be attributed to not only specific surface properties of carbon nanotubes but also in the newly created pores and/or created internal reorganization of crystal network.

The conducted studies proved that the process of thermal desorption of liquids takes place continuously. This fact is evidenced by single inflections on Q-TG curves ('rugged' of Q-TG curves were obtained because computer program was not perfect). The obtained Q-TG and Q-DTG 
curves were used to calculate the adsorption properties of samples, desorption energy of liquids, and the desorption energy distribution functions.

The size of both the surface of micropores $\left(S_{\mathrm{MIKRO}}\right)$ and the specific surface area $\left(S_{\mathrm{BET}}\right)$ was increased by the subjecting of the sample to the action of nitric acid. The increase in the size of the specific surface area is the result of increasing the availability of the internal surface of the nanotubes for the adsorbate. On the basis of the obtained values and shapes of particular curves, it may appear that the modified surface of carbon nanotubes are heterogenic properties and need future investigations by complex and modern techniques. This is supported by bimodal distributions of pore volume distribution in relation to their radius.

Chemical modification of carbon nanotube surface by nitric acid and metal ions caused not only increase of its porosity (e.g., specific surface areas) but also significant changes in adsorption properties with respect to the adsorption of non-polar and polar liquids. The increase of specific surface areas, pore radius, and volumes modified samples may be attributed to the presence of newly created micropores and reorganization of active surface centers.

The influence of adsorption of $\mathrm{Ni}, \mathrm{Co}$, and $\mathrm{Fe} / \mathrm{Co}$ ions on physicochemical properties of carbon nanotube surfaces are similar and complex because the same periodic group of elements are studied. It needs additional studies by means of AFM, EDX, and XRD techniques and will be the subject of our next papers.

Acknowledgements The authors thanks Dr M. Błachnio for providing test results.

Open Access This article is distributed under the terms of the Creative Commons Attribution License which permits any use, distribution, and reproduction in any medium, provided the original author(s) and the source are credited.

\section{References}

1. Schnorr J, Swager TM. Emerging applications of carbon nanotubes. Chem Mater. 2011;23(3):646-57 Review.

2. Lee SW, Kim B-S, Chen S, Horn YS, Hammond PT. Layer-bylayer assembly of all carbon nanotube ultrathin films for electrochemical applications. J Am Chem Soc. 2009;131(2):671-9.

3. Madhukar K, Sainath AVS, Bikshamaiah N, Srinaivas Y, Babu NM, Ashok B, Kumar DS, Rao BS. Thermal properties of single walled carbon nanotubes composites of polyamide 6/poly(metyl metalcrylate) bend system. J Therm Anal Calorim. 2014;115(1): 345-54.

4. Cheng HKF, Chong MF, Lin E, Zhou K, Li L. Thermal decomposition kinetics of multiwalled carbon nanotube/polypropylene nanocomposites. J Therm Anal Calorim. 2014;117(1): 63-71.

5. Staszczuk P, Błachnio M, Sternik D, Dąbrowska E, Wasak S. Studies of physicochemical properties of carbon nanotubes and fullerene. Annals Polish Chem Soc. 2005;2:388-91.
6. Williams KA, Veenhuizen PTM, de la Torre BG, Eritja R, Dekker C. Nanotechnology: carbon nanotubes with DNA recognition. Nature. 2002;420:761. doi:10.1038/420761a.

7. Kang S, Pinault M, Pfefferle LD, Elimelech M. Single-walled carbon nanotubes exhibit strong antimicrobial activity. Langmuir. 2007;23(17):8670-3.

8. Guo Z, Sadler PJ, Tsang SC. Immobilization and visualization of DNA and proteins on carbon nanotubes. Adv Mater. 1998;10: 701-3.

9. Espinoza VS, Erbis S, Pourzahedi L, Eckelman MJ, Isaacs JA. Material flow analysis of carbon nanotube lithium-ion batteries used in portable computers. ACS Sustain Chem Eng. 2014;2(7): 1642-8.

10. Lobez JL, Han SJ, Afzali A, Hannon JB. Surface selective onestep fabrication of carbon nanotube thin films with high density. ACS Nano. 2014;8(5):4954-60.

11. Musumeci AW, Silva GG, Martens WN, Waclawik ER, Frost RL. Thermal decomposition and electron microscopy studies of single-walled carbon nanotubes. J Therm Anal Calorim. 2007;88(3): 885-91.

12. Staszczuk P. World of nanostructures-nanotechnology. Surface properties of chosen nanomaterials determined by adsorption, Q-TG, AFM and SEM methods. J Therm Anal Calorim. 2005;79: 545-54.

13. Gilbertson LM, Goodwin DG, Taylor AD, Pfefferle L, Zimmerman JB. Toward tailored functional design of multi-walled carbon nanotubes (MWNTs): electrochemical and antimicrobial activity enhancement via oxidation and selective reduction. Environ Sci Technol. 2014;48(10):5938-45.

14. Park J, Deria P, Olivier JH, Therien MJ. Fluence-dependent singlet exciton dynamics in length-sorted chirality-enriched single-walled carbon nanotubes. Nano Lett. 2014;14(2):504-11.

15. Staszczuk P. Surface properties of nanoparticles. In: Brown ME, Gallagher PK, editors. Handbook of thermal analysis and calorimetry: recent advances, techniques and applications, vol. 5. Oxford: Elsevier; 2008. p. 343-92.

16. Bethune DS, Kiang CH, De Vries MS, Gorman G, Savoy R. Cobalt-catalysed growth of carbon nanotubes with single-atomiclayer walls. Nature. 1997;363:605-7.

17. Staszczuk P, Błachnio M, Kowalska E, Sternik D. Application of fractal geometry for studies of heterogeneity properties of nanomaterials. J Therm Anal Calorim. 2006;2006(86):51-6.

18. Staszczuk P, Rycyk M. Studies of adsorption and total heterogeneity properties of pure and modified carbon nanotube surfaces. J Therm Anal Calorim. 2013;114:1125-33.

19. Schultze D. Differential thermal analysis. PWN Warsaw; 1974.

20. Paulik F. Special trends in thermal analysis. Chichester: John Wiley \& Sons; 1975.

21. Staszczuk P, Matyjewicz M, Kowalska E, Radomska J, Byszewski P, Kozłowski M. Estimation of sorption properties, total heterogeneity and fractal dimensions of carbon nanotubes. Annals Polish Chem Soc. 2003;2:682-7.

22. Matyjewicz M, Staszczuk P. Fractal dimensions from Q-TG data for estimation of surface heterogeneity. J Therm Anal Calorim. 2003;74:413-22.

23. Pfeifer P. Fractals in physics. Amsterdam: Holland; 1986.

24. Staszczuk P, Sternik D, Chądzyński GW. Determination of total heterogeneous properties and fractal dimension of high-temperature superconductors. J Therm Anal Calorim. 2003;71:173-82.

25. Kisielev AB. The structure and properties of porous materials. London: Butterworths; 1958. p. 195-202.

26. Foo KY, Hameed BH. Insights into the modeling of adsorption isotherm system. Chem Eng J. 2010;156:2-10 Review.

27. McMillan WG, Teller E. The assumption of the BET theory. J Phys Chem. 1951;55(10):17-20. 
28. Staszczuk P. Special applications of thermal analysis in the investigation of liquid/solid systems. Thermochim Acta. 1997;299: $133-40$.
29. Sternik D, Błachnio M, Staszczuk P, Chạdzyński GW, Kowalska E. Total heterogeneity properties of carbon nanomaterials. J Therm Anal Calorim. 2006;86:101-8. 